\title{
Editorial: Deep Carbon in Earth: Early Career Scientist Contributions to the Deep Carbon Observatory
}

\author{
Donato Giovannelli ${ }^{1,2,3,4 *}$, Benjamin A. Black ${ }^{5}$, Alysia D. Cox ${ }^{6,7}$ and Cody S. Sheik ${ }^{8,9}$ \\ ${ }^{1}$ Department of Marine and Coastal Science, Rutgers University, New Brunswick, NJ, United States, ${ }^{2}$ Institute of Marine \\ Science, National Research Council of Italy, Ancona, Italy, ${ }^{3}$ Program in Interdisciplinary Studies, Institute for Advanced \\ Studies, Princeton, NJ, United States, ${ }^{4}$ Earth-Life Science Institute, Tokyo Institute of Technology, Tokyo, Japan, ${ }^{5}$ City \\ College of New York, New York, NY, United States, ${ }^{6}$ Department of Chemistry and Geochemistry, Montana Tech of the \\ University of Montana, Butte, MT, United States, ${ }^{7}$ Department of Geological Sciences and Engineering, Yachay Tech \\ University, Urcuqui, Ecuador, ${ }^{8}$ Department of Biology, University of Minnesota Duluth, Duluth, MN, United States, ${ }^{9}$ Large \\ Lakes Observatory, University of Minnesota Duluth, Duluth, MN, United States
}

Keywords: deep carbon cycle, subsurface, interdisciplinary, early career reasearcher, volcanism, geomicrobiology, geochemistry, carbon minerals

\section{Editorial on the Research Topic}

Deep Carbon in Earth: Early Career Scientist Contributions to the Deep Carbon Observatory

Since its inception, the Deep Carbon Observatory (DCO) has coalesced a multidisciplinary and international group of researchers focused on understanding and quantifying Earth's deep carbon budget. Carbon is the fourth most abundant element in the universe, and understanding carbon chemistry under a variety of environmental conditions impacts all aspects of planetary sciences. DCO recognizes that contributions of early career scientists are integral to the advancement of knowledge regarding the quantities, movements, origins, and forms of Earth's deep carbon. This research topic highlights the contributions of the DCO Early Career Scientist community.

\section{CARBON DEGASSING AT VOLCANOES}

\section{OPEN ACCESS}

Edited and reviewed by: Martyn Tranter,

University of Bristol, United Kingdom

*Correspondence: Donato Giovannelli giovannelli@elsi.jp

Specialty section:

This article was submitted to

Geochemistry,

a section of the journa

Frontiers in Earth Science

Received: 17 October 2017

Accepted: 20 October 2017

Published: 03 November 2017

Citation:

Giovannelli $D, B l a c k B A$, Cox $A D$ and Sheik CS (2017) Editorial: Deep

Carbon in Earth: Early Career Scientist Contributions to the Deep Carbon Observatory. Front. Earth Sci. 5:89. doi: 10.3389/feart.2017.00089
Volcanos are charismatic conduits of Earth's deep carbon, and contribute to gas emissions during eruption episodes and diffuse degassing. Diffuse degassing is a key feature of volcanoes, yet its relationship to volcanic activity is unclear. Epiard et al. show diffuse degassing represents up to $10 \%$ of the total $\mathrm{CO}_{2}$ volcanic output, and find evidence for a shift in the patterns of degassing in the lead-up to eruptions. In a related contribution, Viveiros et al. highlight the pathways that $\mathrm{CO}_{2}$ takes to reach the surface, and show diffuse degassing is concentrated along volcanic-tectonic structures rather than in the vicinity of the youngest volcanic edifices.

\section{THE DEEP EARTH}

Carbonates have been proposed as the principal oxidized carbon-bearing phases in the Earth's interior. Boulard et al. investigated the behavior of $\mathrm{MnCO}_{3}$ at high temperature and pressure and report a phase transition from $\mathrm{MnCO}_{3}$ into $\mathrm{MnCO}_{3}$-II without an accompanying change in the manganese oxidation state until temperatures reached $1,400 \mathrm{~K}$ leading to the formation of manganese oxides and reduced carbon.

$\mathrm{C}-\mathrm{O}-\mathrm{H}$ volatiles are important throughout the lithosphere and are commonly found confined in pores, grain boundaries, and fractures. Gautam et al. present a systematic review of the use of nuclear magnetic resonance (NMR), neutron scattering (NS), and molecular dynamics (MD) simulations to show how application of these three techniques has shed light on the complex behavior of water, $\mathrm{CO}_{2}$, and $\mathrm{C}-\mathrm{O}-\mathrm{H}$ volatiles.

In situ sequestration of $\mathrm{CO}_{2}$ in mantle peridotites has been proposed as a method to alleviate the amount of anthropogenic $\mathrm{CO}_{2}$ in the atmosphere. Lacinska et al. indicate 
a rate of carbonation of $\sim 2 \%$ in half a year, using natural ophiolites, suggesting that serpentinite might be a good host rock for $\mathrm{CO}_{2}$ sequestration.

\section{ACTIVITY OF SUBSURFACE COMMUNITIES}

Microbial communities in deep subsurface environments comprise a significant portion of Earth's biomass, but the microbial activity in these habitats is largely unknown. Hoarfrost et al. present a new fluorescent method to measure extracellular enzymatic activities. The method improves recovery of the labeled substrate from sediment subsamples resulting in greater reliability of quantifying microbially catalyzed hydrolytic activities in sediments.

Yucel et al. show sediment sulfide accumulation is moderated by microbial oxidation at the sediment surface and FeS precipitation in deeper sediment layers, Microorganisms rely on electron flow to drive metabolism and biogeochemical cycles. Taran uses cyclic voltammetry to show that quinone, a microbially produced electron shuttle, interacts and exchanges electrons with pyrite thereby creating a cycle. Using mesocosm incubations, Rajala and Bomberg show rapid microbial response to methane and methanol amendments from two isolated groundwater fractures at $180 \mathrm{~m}$ and $500 \mathrm{~m}$ depths of the Outokumpu Deep Drill hole (Finland). Purkamo et al. used acetate to stimulate microbial community diversity and show treatments dominated by clostridial hydrogenotrophic thiosulfate reducers in fluids obtained from the same Outokumpu Deep Drill hole. Nixon et al. show guar gum stimulates biogenic sulfide production by sulfate-reducing microorganisms at elevated pressure. Their results have implications for the potential role in microbially induced corrosion during hydraulic fracturing operations.

\section{SERPENTINIZATION AND THE CARBON CYCLE}

Serpentinization is of particular interest for deep carbon science, as alteration of ultramafic rocks produce abundant reductants $\left(\mathrm{H}_{2}\right.$ and $\left.\mathrm{CH}_{4}\right)$ that fuel life and sequester significant quantities of carbon. In a groundbreaking interdisciplinary study, Twing et al. show the Coast Range Ophiolite Microbial Observatory serpentinites are low in microbial diversity and dominated by members of the Betaproteobacteria and Clostridia, involved in hydrogen metabolism, carbon monoxide oxidation, carbon fixation, and acetogenesis. Crespo-Medina et al. report the Santa Elena Ophiolite communities are dominated by hydrogen, methane, and methanol oxidizers of the bacterial genera Hydrogenophaga, Methylobacterium, and Methylibium as well as methanogenic Archaea.

\section{CARBON THROUGH TIME AND SPACE}

Changes in the carbon cycle through deep time have astrobiological implications. Brandano et al. show the importance of understanding the role of the slow carbon cycle through deep time using extant data of seagrass productivity along the Mediterranean Sea and integrating GPlate models. Azua-Bustos et al. present a compelling case for the study of the physiological and molecular mechanisms utilized by heterotrophic microorganisms to detect, mobilize, incorporate, and use carbon under extremely harsh conditions in the Atacama Desert in Chile with astrobiological significance.

\section{BUILDING A CARBON NETWORK}

Building a large community of interdisciplinary scientists focused on studying the different aspects of deep carbon science requires also creating a supporting infrastructure to foster community growth and facilitate information exchange. Ma et al. describe how the DCO has leveraged state of the art information technologies to establish a knowledge network, which promotes collaboration, reproducibility, accreditation, and stimulates new ideas across deep carbon related studies.

\section{AUTHOR CONTRIBUTIONS}

DG, BB, AC, and CS have all equally contributed to this editorial.

\section{FUNDING}

This publication was supported by Alfred P. Sloan Foundation grants G2014-13728 to DG, CS, and AC. DG was also supported by Alfred P. Sloan Foundation grant G2016-7206, National Science Foundation grant MCB 15-17567 and by the ELSI Origins Network (EON), which is supported by a grant from the John Templeton Foundation. The opinions expressed in this publication are those of the author(s) and do not necessarily reflect the views of the John Templeton Foundation. DG was also partly supported by a C-DEBI (Center for Dark Energy Biosphere Investigation) postdoctoral fellowship. BB was supported by National Science Foundation grant 1615147. AC was supported by NASA Exobiology Award NNX-16AJ61G.

\section{ACKNOWLEDGMENTS}

We are grateful to the Deep Carbon Observatory and the Alfred P. Sloan Foundation for their continuous support to early career scientists. We also wish to thank Katie Pratt for help in crafting the idea of this Research Topic. This is C-DEBI contribution 396. Conflict of Interest Statement: The authors declare that the research was
conducted in the absence of any commercial or financial relationships that could
be construed as a potential conflict of interest.

Copyright (c) 2017 Giovannelli, Black, Cox and Sheik. This is an open-access article distributed under the terms of the Creative Commons Attribution License (CC BY). The use, distribution or reproduction in other forums is permitted, provided the original author(s) or licensor are credited and that the original publication in this journal is cited, in accordance with accepted academic practice. No use, distribution or reproduction is permitted which does not comply with these terms. 